\title{
INTERPRETIVE SUMMARIES, SEPTEMBER 2015
}

Personality and production: Nervous cows produce less milk. By Hedlund and Løvlie, page 5819. We investigated the relationship between variation in animal personality and production traits in dairy cows. Behaviors were scored during milking in response to novel object and social separation. We demonstrated that cows that step more during milking or that respond more strongly to social separation have lower milk production. These results are of interest to researchers in animal personality and animal production and welfare, and may have implications for improvement of milk production and welfare of dairy cows.

http://dx.doi.org/10.3168/jds.2014-8667.

The composition and functional properties of whey protein concentrates produced from buttermilk are comparable with those of whey protein concentrates produced from skimmed milk. By Svanborg et al., page 5829. Sweet buttermilk (BM) from industrial churning and pasteurized skimmed milk were microfiltered $(0.2 \mu \mathrm{m})$ to produce whey protein concentrates (WPC). The WPC obtained from the microfiltration permeate of BM (BMWPC) was equivalent to the WPC of pasteurized SM (SMWPC) in solubility, foaming properties and chemical composition. The BMWPC powder had a higher amount of fat and less lactose and casein compared with SMWPC. The 2 WPC differed in their protein contents and phospholipid compositions; however, they had comparable total phospholipid contents and functional properties. http://dx.doi.org/10.3168/jds.2014-9039.

In vitro probiotic characteristics of Lactobacillus plantarum ZDY 2013 and its modulatory effect on gut microbiota of mice. By Huang et al., page 5850. The purpose of this study was to investigate the novel strain Lactobacillus plantarum ZDY 2013, isolated from Chinese homemade acid beans. We systematically assessed its survival under stress conditions $(\mathrm{pH}$, bile salt, simulated gastrointestinal tract, and antibiotics), and in vivo interaction with indigenous microbiota using quantitative real-time polymerase chain reaction and denaturing gradient gel electrophoresis. The ZDY 2013 strain exhibited high stress resistance and possessed antibacterial and gut microbiota modulation properties with potential application in the development of dairy food and nutraceuticals.

http://dx.doi.org/10.3168/jds.2014-9153.

Microbial cell-free extracts as sources of enzyme activities to be used for enhancement flavor development of ewe milk cheese. By Calasso et al., page 5874. Freeze-dried cell-free extracts (CFE) from selected microorganisms were used as sources of enzyme activities for conditioning the ripening of ewe milk cheese. The primary and the secondary proteolysis of the cheeses with added CFE were markedly affected, as were the levels of several volatile compounds. The cheeses with added CFE showed higher sensory attributes than the control cheese. Overall, cheese ripening was accelerated or conditioned by using CFE as a source of tailored enzyme activities.

http://dx.doi.org/10.3168/jds.2015-9362.

Pulsed-light inactivation of pathogenic and spoilage bacteria on cheese surface. By Proulx et al., page 5890. Cheese products made from pasteurized milk are susceptible to surface bacterial contamination during slicing, handling, or packaging, which can lead to food safety issues and significant losses due to spoilage. Pulsed-light treatment is a rapid, nondestructive technology that could address this problem. This study shows that pulsed-light can effectively inactivate relevant pathogenic and spoilage bacteria on Cheddar and process cheese, even when the product is prepackaged in clear polyethylene packaging.

http://dx.doi.org/10.3168/jds.2015-9410.

Effect of essential oils of Syzygium aromaticum and Cinnamomum zeylanicum and their major components on biofilm production in Staphylococcus aureus strains isolated from milk of cows with mastitis. By Budri et al., page 5899. The production of biofilm by Staphylococcus aureus is a problem in industry because this could facilitate the adhesion of bacteria to solid surfaces and contribute to the transmission of these bacteria during food production. This work aimed to investigate the effect of the essential oils of Syzygium aromaticum (clove) and Cinnamomum zeylanicum (cinnamon) and their major components, eugenol and cinnamaldehyde, on Staph. aureus biofilm formation on different surfaces. The activity of these substances on stainless steel and polystyrene indicates their potential as an alternative sanitizing spray for surface cleaning in the food processing industry.

http://dx.doi.org/10.3168/jds.2015-9442.

Solubilization of rehydrated frozen highly concentrated micellar casein for use in liquid food applications. By Lu et al., page 5917. Highly concentrated micellar casein concentrate (HC-MCC) is a gel at cold temperature; it contains $\sim 20 \%$ casein with most serum proteins and lactose removed by successive microfiltration, diafiltration, and vacuum evaporation of skim milk. Investigating the solubility of rehydrated frozen HC-MCC could help determine its potential as a protein-fortification ingredient in liquid food systems. Our objective was to solubilize rehydrated frozen HCMCC using different shear speed and time combinations, mixing temperatures, $\mathrm{pH}$, and extended time. To 
better understand the factors contributing to solubility, we studied rheological properties and microstructure of HC-MCC gel.

http://dx.doi.org/10.3168/jds.2015-9482.

Nano spray-dried sodium chloride and its effects on the microbiological and sensory characteristics of surface-salted cheese crackers. By Moncada et al., page 5946. Reducing the particle size of salt to approximately $1.5 \mu \mathrm{m}$ would increase its surface area, leading to an increased dissolution rate in saliva and a more efficient transfer of the ions to the taste buds and thus perhaps a saltier perception of foods. This has potential for reducing the level of salt in surface-salted foods. The objectives were (1) to develop a salt using a nano spray-drying method, (2) to use the developed nano spray-dried salt in surface-salted cheese cracker manufacture, and (3) to evaluate the microbiological and sensory characteristics of the cheese crackers. Results indicated that when regular salt particle size was reduced $3 \log$ (from 1,500 to $1.5 \mu \mathrm{m}$ ) to form nano spray-dried salt, comparable microbiological and sensory quality parameters were obtained, allowing the use of 25 to $50 \%$ less salt in the nano spray-dried form.

http://dx.doi.org/10.3168/jds.2015-9658.

Effect of insoluble calcium concentration on the endogenous syneresis rate in rennet-coagulated bovine milk. By Choi et al., page 5955. A critically important property of rennet-induced milk gels is their ability to rapidly synerese or shrink (expelling moisture). This ability is exploited in the cheese-making process to facilitate a significant reduction in moisture content (and thereby increase shelf life). We applied a modified rheological model of the gelation process to account for the observed decrease in the gel modulus with aging time. This decay term was ascribed to the syneresis process, and the modified model successfully fitted various experimental curves made from milks with various levels of insoluble calcium phosphate.

http://dx.doi.org/10.3168/jds.2015-9527.

Effect of yogurt containing deep sea water on health-related serum parameters and intestinal microbiota in mice. By Kang et al., page 5967. Deep sea water (DSW) and yogurt improve human health. We believe that addition of DSW to yogurt enhances the health benefits of yogurt. Thus, this study estimated the effect of DSW-containing yogurt compared with normal yogurt consumption on blood and intestinal microorganisms using mice. Both the DSW yogurt and normal yogurt decreased chronic disease indices (serum aspartate aminotransferase and alanine aminotransferase levels) and increased healthful lactic acid bacteria in the intestine. The DSW yogurt had a more positive effect on serum cholesterol than did the normal yogurt. http://dx.doi.org/10.3168/jds.2015-9492.
Stability of nonfouling electroless nickelpolytetrafluorethylene coatings after exposure to commercial dairy equipment sanitizers. $B y$ Huang and Goddard, page 5983. Nonfouling coatings on stainless steel may enable improved operational efficiency, quality, and safety of thermally processed fluid dairy products. There remains a need for thorough characterization of the stability of such coating technologies after exposure to chemical agents common in dairy equipment sanitization and cleaning protocols. Herein, we report on the stability of nickel-polytetrafluorethylene (Ni-PTFE) coatings on stainless steel after exposure to chlorine-, peroxide-, and iodine-based sanitizers. Coatings suffered delamination or corrosion after extended exposure to iodine- and chlorine-based sanitizers, but retained nonfouling properties with no observable degradation even after extended exposure to peroxide-based sanitizers.

http://dx.doi.org/10.3168/jds.2015-9714.

Cupuassu (Theobroma grandiflorum) pulp, probiotic, and prebiotic: Influence on color, apparent viscosity, and texture of goat milk yogurts. By Costa et al., page 5995. Cupuassu is a fruit native to the Brazilian Amazon, and it has a characteristic aroma, flavor, and texture. Goat milk is a food of high biological value. However, compared with cow and sheep yogurts, goat milk yogurts do not naturally have an appropriate consistency, which complicates the production and acceptance of this product. In this study, we used different ingredients (cupuassu pulp, probiotic, and prebiotic) to improve the texture of goat milk yogurt. The different treatments were evaluated for color, $\mathrm{pH}$, apparent viscosity, and texture to assess their potential value as additives.

http://dx.doi.org/10.3168/jds.2015-9738.

Prediction of instrumental texture and melting characteristics of process cheese using dielectric spectroscopy and chemometrics. By Amamcharla and Metzger, page 6004. A dielectric spectroscopy-based method was developed for determination of melted and unmelted properties of process cheese. Dielectric spectra of process cheese from 3 different sets of samples were collected and subsequently used to develop statistical and neural network models. The ratio of prediction error to deviation was $>2$ for melt diameter and hardness, indicating good practical utility of the statistical prediction models. Overall, dielectric spectroscopy coupled with chemometrics could be a useful tool for the nondestructive measurement of functional properties of process cheese.

http://dx.doi.org/10.3168/jds.2015-9739.

Short communication: Characterization of soluble thiols in bovine milk. By Niero et al., page 6014 . Low-molecular-weight (LMW) thiols are antioxidant 
compounds with positive effects on human health. This study aimed to characterize LMW thiols in milk from 2 dairy and 2 dual-purpose cattle breeds using reversephase HPLC. The analysis detected 6 thiol species, and 2 of them [glutathione (GSH), and cysteine-glycine (Cys-Gly)] were identified and quantified. Correlations of Cys-Gly with protein and casein contents were moderately low. The average concentration of Cys-Gly was greater than that of GSH across all cattle breeds. Milk from dual-purpose breeds was richer in LMW thiols than milk from dairy cows.

http://dx.doi.org/10.3168/jds.2015-9740.

Intravaginally administered lactic acid bacteria expedited uterine involution and modulated hormonal profiles of transition dairy cows. By Deng et al., page 6018. In this study, we evaluated the potential of intravaginally administered lactic acid bacteria $(\mathrm{LAB})$ on expediting uterine involution and improving reproductive performance of postparturient dairy cows. Our data demonstrated that administering 2 doses of LAB before calving or 3 doses around calving was able to expedite involution of the uterus and affect hormones that regulate reproduction. Prepartum LAB also decreased the calving to conception interval.

http://dx.doi.org/10.3168/jds.2014-8559.

An investigation of the dynamics of intramammary infections acquired during the dry period in European dairy farms. By Bradley et al., page 6029. The importance of the dry period in mastitis epidemiology has been widely acknowledged. However, our understanding of this period has been based on a relatively small number of studies conducted in a limited geographical location. This multicentered, international study has investigated intramammary infection dynamics in 12 herds across 6 jurisdictions and revealed significant variation in the cause of intramammary infection and the proportions of cows affected in different herds, suggesting that practitioners need to be more circumspect in their approach to dry period management and mindful of local conditions.

http://dx.doi.org/10.3168/jds.2014-8749.

Consequences and economics of metritis in Iranian Holstein dairy farms. By Mahnani et al., page 6048. Metritis is one of the most common reproductive and costly diseases in dairy cattle. Incidence, risk factors, and production and reproduction consequences of metritis were investigated in this study. Results can be used in cost-benefit analyses for management factors in metritis control programs. The proposed model can also be used to calculate economic losses due to metritis in other developing countries where farm production and economic data are generally scarce.

http://dx.doi.org/10.3168/jds.2014-8862.
The effects of firocoxib on cautery disbudding pain and stress responses in preweaned dairy calves. By Stock et al., page 6058. Consideration of pain control in livestock production practices, such as dehorning in cattle, is critical to maintaining consumer confidence. Here, we characterize the nociception and distress response following cautery disbudding. Furthermore, we evaluate the effect of the one-time oral administration of firocoxib, a long-acting nonsteroidal antiinflammatory drug (NSAID), on providing analgesia following disbudding.

http://dx.doi.org/10.3168/jds.2014-8877.

Cost-benefit analysis of vaccination against Mycobacterium avium ssp. paratuberculosis in dairy cattle, given its cross-reactivity with tuberculosis tests. By Groenendaal et al., page 6070 . This study used data from a vaccination field trial and an epidemiologic and economic simulation model to identify circumstances in which vaccination against Johne's disease (JD) in dairy cattle is economically attractive, taking into account the indirect costs due to cross-reactivity of MAP vaccination with the bovine tuberculosis (BTB) program. The study found positive, direct economic benefits of MAP vaccination on infected herds, which were higher than indirect costs due to cross-reactivity, making MAP vaccination overall economically attractive. Vaccination is not economically attractive in regions with a high BTB testing frequency or where typically small groups of animals are BTB tested.

http://dx.doi.org/10.3168/jds.2014-8914.

The effects of providing portable shade at pasture on dairy cow behavior and physiology. $B y$ Palacio et al., page 6085. We examined the behavior and physiology differences between cows with access to portable shades and cows without access to any shade. Behaviors were observed during the hottest portions of the day, and milk production and vaginal temperature were automatically recorded. Our results showed that providing cows with access to pasture does not have detrimental effects on cows or their production, and that providing access to shade may help decrease production costs and environmental impact by decreasing cow water consumption.

http://dx.doi.org/10.3168/jds.2014-8932.

Lactation traits associated with short-and longterm once-daily milking performance in New Zealand crossbred dairy cattle. By Davis et al., page 6094. Sources of variation in milk production and production responses to once-daily milking (ODM) were examined in short- and long-term studies with cross-bred dairy cattle. Cow performance on once-daily milking was highly correlated with previous twice-daily 
production, with a small part of the variance attributable to somatic cell count. The percentage of milk left in the udder after milking (i.e., residual milk) was moderately correlated with the loss of milk production after 1 wk of ODM and milk production over a full lactation of ODM.

http://dx.doi.org/10.3168/jds.2014-8948.

Suitability of capillary blood obtained by a minimal invasive lancet technique to detect subclinical ketosis in dairy cows by using 3 different electronic hand-held devices. By Kanz et al., page 6108. Subclinical ketosis is known as predisposing factor for the occurrence of many secondary diseases in dairy cows. Early detection and treatment of this metabolic disorder is important for animal welfare as well as for the economic efficiency of stock management. In this study, we evaluated the suitability of capillary blood obtained by a minimal invasive lancet technique to detect subclinical ketosis in dairy cows using different electronic hand-held devices.

http://dx.doi.org/10.3168/jds.2014-8957.

Transcriptome profiles of whole blood in Italian Holstein and Italian Simmental lactating cows diverging for genetic merit for milk protein. $B y$ Sandri et al., page 6119. Genetic selection through estimated breeding values (EBV) has improved milk, fat, and protein yields over the past decades, but many of the genetic and genomic variations underpinning these improvements are not completely elucidated. The present study compares blood gene expression of Italian Simmental and Italian Holstein cows in mid-lactation with diverging EBV for milk protein yield. Metabolism of major nutrients and glutathione were the most affected pathways in Italian Simmental cows with different EBV. In Italian Holstein cows, immune system pathways were most affected. These metabolic and immunological pathways were shown to be directly related to genetic merit and could be considered a signature of the quantitative selection.

http://dx.doi.org/10.3168/jds.2014-9049.

Ketonemia in dairy goats: Effect of dry period length and effect on lying behavior. By Zobel et al., page 6128. Ketonemia, an indicator of negative energy balance, and lying behavior of 420 goats were monitored on 10 commercial dairy goat farms. Does that developed ketonemia had longer dry periods compared with does that remained healthy. Ketonemic does had reduced lying behavior around kidding compared with goats that remained healthy. Monitoring lying behavior can help in the early identification of goats becoming ketonemic.

http://dx.doi.org/10.3168/jds.2014-9136.
Glucose supplementation has minimal effects on blood neutrophil function and gene expression in vitro. By Garcia et al., page 6139. Glucose supplementation has minimal effects on blood neutrophil function and gene expression in vitro. Glucose supply during early lactation is low and the effect on neutrophil function is poorly understood. This study evaluated the effect of glucose supply on neutrophil function for cows in early and mid lactation. Glucose altered neutrophil function in vitro but had minimal effects on gene expression. Stage of lactation resulted in minimal changes in neutrophil response to glucose supply. Metabolic profiles for cows in early lactation did not parallel those for cows during the early postpartum period and may partly explain results. Future research investigating the relationship between glucose supply and immune cell function during lactation is warranted. http://dx.doi.org/10.3168/jds.2014-9183.

Influence of grazing management on claw disorders in Swedish freestall dairies with mandatory grazing. By Bergsten et al., page 6151. Grazing is thought to improve locomotion and reduce claw disease and lameness. Routines for grazing and housing management were collected from 201 telephone-interviewed farmers with freestall herds. Claw records were retrieved from maintenance foot trimming before and after the grazing period. Pasture stocking density and amount of grazing per 24 hours was associated with the prevalence of dermatitis and sole ulcer. The greatest influence on a claw disorder after the grazing period was the presence of the same claw disorder before release to pasture, which can be assumed to be an effect from the housing period.

http://dx.doi.org/10.3168/jds.2014-9237.

Growth, ruminal measurements, and health characteristics of Holstein bull calves fed an $A s$ pergillus oryzae fermentation extract. By Yohe et al., page 6163. A fermentation extract of the fungus Aspergillus oryzae (AMF) can be utilized as a prebiotic. Objectives were to determine if dietary inclusion of AMF would alter growth, intake, ruminal, and health measurements of purchased immunocompetent Holstein bull calves from birth through 1 wk postweaning. Fifty two calves were used in this experiment. The AMF was fed to the treatment group at $2 \mathrm{~g} / \mathrm{d}$. Overall, calves in both groups had similar measures of feed intake, growth, and health; these measurements were similar to those reported in contemporary studies.

http://dx.doi.org/10.3168/jds.2015-9313.

Macrophage infiltration in the omental and subcutaneous adipose tissues of dairy cows with displaced abomasum. By Contreras et al., page 6176 . Excessive negative energy balance (NEB) during the 
transition period increases lipolysis from adipose tissues, predisposing cows to diseases such as displaced abomasum (DA). This study characterized adipose tissue macrophage (ATM) infiltration into different adipose tissue depots in cows with DA and intense lipolysis. These cows had a significant infiltration of ATM in omental and subcutaneous adipose tissue that was localized in multiple aggregates. Together, these results indicate that ATM infiltration is a concurrent finding in DA cases and may be associated with uncontrolled lipolysis processes in transition dairy cows.

http://dx.doi.org/10.3168/jds.2015-9370.

Polyunsaturated fatty acids influence differential biosynthesis of oxylipids and other lipid mediators during bovine coliform mastitis. $B y$ Mavangira et al., page 6202. Escherichia coli is a major cause of severe clinical mastitis of dairy cows. The current study evaluated how changes in fatty acid composition influences the generation of metabolites, known as oxylipids, crucial for regulating inflammatory responses during acute coliform mastitis. This study showed significant elevations of many oxylipids and their fatty acid substrates during coliform mastitis. Results of this study also showed that fatty acid substrates, pathway, and extent of metabolism influence oxylipid profiles. The current study demonstrates various opportunities for evaluating intervention strategies to limit damage to the mammary gland, death of animals, and economic losses due to coliform mastitis.

http://dx.doi.org/10.3168/jds.2015-9570.

Antimicrobial susceptibilities and random amplified polymorphic DNA-PCR fingerprint characterization of Lactococcus lactis ssp. lactis and Lactococcus garvieae isolated from bovine intramammary infections. By Plumed-Ferrer et al., page 6216. The aims of this study were to detect minimum inhibitory concentrations of 17 antimicrobials in 46 Lactococcus lactis ssp. lactis and 47 Lactococcus garvieae isolated from intramammary infections and compare genotypic characteristics of isolates. No resistant strains were found for the $\beta$-lactam antibiotics widely used in clinical practice (penicillin, ampicillin, and amoxicillin), and all minimum inhibitory concentrations were far from the resistance breakpoints.

http://dx.doi.org/10.3168/jds.2015-9579.

Effects of space allowance on the behavior and physiology of cattle temporarily managed on rubber mats. By Schütz et al., page 6226. Cows in pasture-based dairy systems are sometimes temporarily managed off pasture, particularly in wet weather to reduce soil damage. Such stand-off practices may influence the welfare of animals. Cows were managed off pasture on rubber matting for 3 consecutive days (18 $\mathrm{h} / \mathrm{d})$ at different space allowances $(3.0,4.5,6.0,7.5,9.0$, and $10.5 \mathrm{~m}^{2} / \mathrm{cow}$ ). Lying times increased and aggressive behavior and lying disturbances were less frequent with increasing space allowance. At lesser space allowances, cows were dirtier and spent more time lying on pasture between stand-off periods when they were offered their daily feed allowance.

http://dx.doi.org/10.3168/jds.2015-9593.

Development and validation of a novel pedometer algorithm to quantify extended characteristics of the locomotor behavior of dairy cows. By Alsaaod et al., page 6236. With the size of dairy herds increasing in recent years, systems for automated detection of locomotor behavior of cows are increasingly useful for the dairy industry. This study was carried out to develop and validate a novel pedometer algorithm, allowing for the description of several characteristics of walking, standing, and lying behavior with a moderate to high correlation between pedometer output and manual observation. The combination of the pedometer and the novel algorithm could be useful for real-time detection of normal and pathological behavior of loosehoused dairy cows.

http://dx.doi.org/10.3168/jds.2015-9657.

Five-day resynchronization programs in dairy cows, including presynchronization and progesterone at two stages following artificial insemination. By Pulley and Stevenson, page 6243. Resynchronization (RES) was carried out after a nonpregnant diagnosis on d 35 or 41. A 5-d RES program applied to 1,031 cows on d 35 reduced pregnancy per AI (P/AI) when progesterone insert-treated cows had blood progesterone $\geq 1 \mathrm{ng} / \mathrm{mL}$ on $\mathrm{d} 35$, but the reverse was true in when blood progesterone was $<1$ $\mathrm{ng} / \mathrm{mL}$ compared with controls. Presynchronization of 624 nonpregnant cows with prostaglandin $\mathrm{F}_{2 \alpha}$ and gonadotropin-releasing hormone 10 and $7 \mathrm{~d}$ before a 5 -d RES d 41 with or without progesterone inserts had greater insemination risk than d 41 RES cows, but P/ AI did not differ among treatments.

http://dx.doi.org/10.3168/jds.2015-9660.

Diversity and antimicrobial susceptibility profiling of staphylococci isolated from bovine mastitis cases and close human contacts. By Schmidt et al., page 6256. Little data are currently available regarding the diversity of staphylococcal species causing intramammary infections (IMI) in South African dairy herds and the susceptibility of these species to different antimicrobials. The purpose of this study was to address the current knowledge gap by analyzing staphylococci recovered from 13 dairy operations in the province of KwaZulu-Natal, South Africa. Additionally, sampling of close human contacts in the dairy environ- 
ment was carried out to investigate the staphylococcal populations in human hosts and compare them with bovine staphylococci. The results provide invaluable information to assist with the treatment and prevention of IMI in dairy cows.

http://dx.doi.org/10.3168/jds.2015-9715.

Short communication: Use of the BetaStar Plus assay for detection of ceftiofur antimicrobial residues in milk from individual cows treated intramammary for mastitis. By Grooms et al., page 6270. Development of on farm tests to detect antibiotics in milk would be useful to reduce risks of residues in milk sold to consumers. Milk samples from cows treated with the antibiotic ceftiofur were tested with a rapid point-of-care assay (BetaStar Plus, Neogen Inc, Lansing, MI) and compared with results obtained using liquid chromatography-tandem mass spectrometry (LC-MS/MS). The BetaStar Plus assay had sensitivity and specificity of 100 and $84.7 \%$, respectively, compared with LC-MS/MS results. The BetaStar Plus assay could be useful to detect ceftiofur residues in milk from individual cows treated for mastitis before being included in the bulk tank and shipped for processing. http://dx.doi.org/10.3168/jds.2014-8802.

Short communication: Localization and expression of the monocyte chemoattractant protein-1 in different subcutaneous and visceral adipose tissues of early lactating dairy cows. By Häussler et al., page 6278. Early lactation is mostly accompanied by massive fat mobilization, decreased insulin sensitivity, and compromised immune function. Although only marginal immune cells infiltrate into bovine adipose tissue, the monocyte chemoattractant protein-1 was present in subcutaneous and visceral adipose tissue from early-lactating dairy cows. The effect of dietary conjugated linoleic acid supplementation on mRNA abundance and protein expression of MCP-1 observed in the present study was negligible.

http://dx.doi.org/10.3168/jds.2014-9256.

Short communication: Concentrations of nonesterified fatty acids and $\beta$-hydroxybutyrate in dairy cows are not well correlated during the transition period. By McCarthy et al., page 6284. Nonesterified fatty acids (NEFA) and $\beta$-hydroxybutyrate (BHBA) are considered candidate markers of negative energy balance in transition cows. Elevation of either of these markers has been shown to have negative associations with cow performance. The objective of this study was to describe the patterns of blood NEFA and BHBA concentrations over time to describe the temporal relationship and correlation between NEFA and BHBA during the periparturient period. Overall, there is a weak relationship between these markers and cau- tion should be exerted when trying to extrapolate interchangeable relationships between NEFA and BHBA data.

http://dx.doi.org/10.3168/jds.2015-9446.

Effects of varying dietary ratios of corn silage to alfalfa silage on digestion of neutral detergent fiber in lactating dairy cows. By Lopes et al., page 6291. The objective was to compare estimates of fiber digestion predicted from in vitro fiber digestibility analysis of diets to fiber digestion measured in lactating cows fed the same diets. Diets were analyzed by an in vitro assay to predict potentially digestible neutral detergent fiber (NDF) and rate of NDF digestion. The in vitro data were applied in a model to predict total-tract NDF digestibility. Similar diets were fed to lactating dairy cows and fiber digestibility was measured. Fiber digestibility measured in vivo was similar to those predicted from the model based on the in vitro assay. http://dx.doi.org/10.3168/jds.2014-8662.

Supplementation of prepartum dairy cows with 3-carotene. By Oliveira et al., page 6304. We evauated the prepartum supplementation of $\beta$-carotene to dairy cows fed preserved forages. The supplementation of $\beta$-carotene increased plasma $\beta$-carotene content around calving and was associated with a lower incidence of retained placenta in multiparous cows but had no effect on lactation performance and reproductive efficiency. http://dx.doi.org/10.3168/jds.2014-9037.

Weaning age affects growth, feed intake, gastrointestinal development, and behavior in Holstein calves fed an elevated plane of nutrition during the preweaning stage. By Eckert et al., page 6315. The objective of this study was to determine the influence of weaning age on feed intake, growth, development, and behavior of dairy calves fed an elevated plane of nutrition. The results suggest that calves fed an elevated plane of nutrition preweaning benefit from extending the time of weaning from 6 to 8 wk of age, based on energy intake, growth, gastrointestinal function, and behavior measurements. These findings provide insight into calf biology and development that can be directly used in modern production systems. http://dx.doi.org/10.3168/jds.2014-9062.

Effects of dietary Capsicum oleoresin on productivity and immune responses in lactating dairy cows. By Oh et al., page 632\%. The results from this study suggest that dietary supplementation of Capsicum oleoresin had subtle or no effect on feed intake, rumen fermentation parameters, nutrients digestibility, blood chemistry, T-cell phenotypes, and antioxidant status in dairy cows. However, it appeared to facilitate neutrophil activity and immune cells related to acute 
phase response and increased energy-corrected milk yield.

http://dx.doi.org/10.3168/jds.2014-9294.

Updating the Cornell Net Carbohydrate and Protein System feed library and analyzing model sensitivity to feed inputs. By Higgs et al., page 6340. The Cornell Net Carbohydrate and Protein System (CNCPS) is a model that enables the formulation of diets that closely match animal requirements. The model includes a library of approximately 800 feed ingredients that provide the platform for describing the chemical composition of the ration. A procedure was developed to review and update the feed library using datasets from commercial laboratories. The updated feed library provides a database of ingredients that are consistent with current laboratory data and enables more precise predictions of dietary energy and protein supply.

http://dx.doi.org/10.3168/jds.2015-9379.

The Cornell Net Carbohydrate and Protein System: Updates to the model and evaluation of version 6.5. By Van Amburgh et al., page 6361. The first version of The Cornell Net Carbohydrate and Protein System (CNCPS) was published in 1992, and it is used as a formulation and evaluation platform worldwide to formulate diets for cattle. This paper describes changes made to CNCPS version 6.0, resulting in CNCPS version 6.5, and presents a model evaluation against both literature and on-farm data. Updates made the model more accurate and precise in predicting nutrient availability and milk production. Further, the changes implemented in the model allows for the formulation of lower crude protein diets while maintaining milk production, which allows nutritionists to reduce nitrogen excretion and improve nutrient management at the farm level.

http://dx.doi.org/10.3168/jds.2015-9378.

Early pair housing increases solid feed intake and weight gains in dairy calves. By Costa et al., page 6381. Milk-fed calves are typically housed individually, but social housing may increase calf feed intake. The aim of this study was to assess the effects of early (6 d of age) and late (43 d of age) pairing on feeding behavior and weight gains in Holstein dairy calves. Calves paired soon after birth had higher intake of solid feed and the highest body weight gains compared with late paired and individually housed calves. These results indicate that calves can benefit from early social housing. http://dx.doi.org/10.3168/jds.2015-9395.

Risk factors for quinolone-resistant Escherichia coli in feces from preweaned dairy calves and postpartum dairy cows. By Duse et al., page $638 \%$. Quinolone-resistant Escherichia coli (QREC) in food animals may infect the animal or spread to humans via food. We found that calves $<18 \mathrm{~d}$ of age shed more QREC than older calves, in particular those that were fed milk from cows treated with antibiotics. The QREC were also more common on farms that purchased cattle, shared animal transports with other farms, had shared calving pens, and had poor hygiene. Changing routines on farms may therefore decrease the occurrence of QREC.

http://dx.doi.org/10.3168/jds.2015-9453.

Apparent recovery of C18 polyunsaturated fatty acids from feed in cow milk: A meta-analysis of the importance of dietary fatty acids and feeding regimens in diets without fat supplementation. By Khiaosa-ard et al., page 6399. A statistical review of published results showed that milk C18 fatty acids secretion in milk increases with their content in cow diets. However, the transfer efficiency from feed to milk followed a nonlinear and inverse relationship to their dietary content, indicating a homeostatic regulation. Independent of fatty acid intake, feeding regimen affected milk fatty acid composition, too. With barnfeeding, C18 fatty acid recovery responded to dietary alterations of $\alpha$-linolenic acid, whereas grazing brought about unknown factors other than dietary fatty acids. http://dx.doi.org/10.3168/jds.2015-9459.

Supplementing fresh bovine colostrum with gutactive carbohydrates reduces passive transfer of immunoglobulin $\mathbf{G}$ in Holstein dairy calves. $B y$ Brady et al., page 6415 . The addition of a gut-active carbohydrate to fresh maternal colostrum inhibited the intestinal absorption of maternal antibodies by neonatal calves: calves fed colostrum supplemented with $30 \mathrm{~g}$ of gut-active carbohydrates had lower serum immunogobulin G ( $\operatorname{IgG}$ ) concentrations and lower apparent efficiency of absorption of IgG at $24 \mathrm{~h}$ after birth compared with calves fed nonsupplemented colostrum. http://dx.doi.org/10.3168/jds.2015-9481.

Effects of direct-fed Bacillus pumilus 8G-134 on feed intake, milk yield, milk composition, feed conversion, and health condition of pre- and postpartum Holstein cows. By Luan et al., page 6423. Direct-fed microbials (DFM) have been studied to manipulate the microbial ecosystem and fermentation characteristics in the rumen and intestinal tracts of livestock animals. The outcomes from the present study are complementary and consistent with the fact that dairy cows receiving DFM (Bacillus pumilus 8G134) had a more metabolically sound transition period, improved immunity in the mammary gland, and higher feed conversion in early lactation compared with cows not receiving DFM.

http://dx.doi.org/10.3168/jds.2015-9512. 
Long-term reticuloruminal $\mathrm{pH}$ dynamics and markers of liver health in early-lactating cows of various parities fed diets differing in grain processing. By Humer et al., page 6433. Rumen and systemic metabolic disorders are a health concern in early-lactating dairy cattle. This study evaluated the effects of grain processing and parity on reticuloruminal $\mathrm{pH}$ and markers of liver health in early-lactating cows. The data showed that feeding barley grain steeped in lactic acid affected the time of $\mathrm{pH}$ below the threshold of subacute rumen acidosis. Although the duration of low $\mathrm{pH}$ was reduced in first-production heifers fed barley grain treated with lactic acid, the opposite effect was observed in multiparous cows. Nevertheless, liver health-related variables and acute phase response were not affected by grain processing technique. In general, primiparous cows showed longer periods of low reticuloruminal $\mathrm{pH}$ compared with multiparous cows.

http://dx.doi.org/10.3168/jds.2015-9522.

Effect of biotin and pantothenic acid on performance and concentrations of avidin-binding substances in blood and milk of lactating dairy cows. By Ferreira et al., page 6449. Biotin and pantothenic acid are $2 \mathrm{~B}$ vitamins that are known to be absorbed through the same mechanism in the gastrointestinal tract of nonruminant species. We hypothesized that supplementing high concentrations of pantothenic acid would interfere with the absorption of biotin in lactating dairy cows. Contrary to our hypothesis, pantothenic acid did not affect the concentrations of biotin or biotin metabolites in blood and milk. We therefore concluded that pantothenic acid does not interfere with the absorption of biotin in lactating dairy cows.

http://dx.doi.org/10.3168/jds.2015-9620.

Effects of cultivar and grazing initiation date on fall-grown oat for replacement dairy heifers. By Coblentz et al., page 6455. Fall-grown oat shows promise for fall grazing, but the optimum date to initiate grazing has not been determined. Heifer growth performance was evaluated from pastures seeded to Ogle or ForagePlus oat with early (late-September) or late (mid-October) grazing initiation dates. These results do not support delaying grazing until mid-October because of (1) potential forced early termination of grazing due to extensive snow cover; (2) sharp year-to-year differences in maturation rate by grain-type cultivars that may make the forage less acceptable to heifers; and (3) inadequate time for heifers to adapt properly to grazing routines while also adapting to sub-freezing temperatures.

http://dx.doi.org/10.3168/jds.2015-9639.

Extruded soybean meal increased feed intake and milk production in dairy cows. By Giallongo et al., page 6471. This crossover experiment showed that replacing solvent-extracted soybean meal with equivalent amounts of extruded soybean meal in the diets of lactating dairy cows increased feed intake and milk yield. The extruded soybean meal diets, which had higher fat content, decreased the concentration of total saturated fatty acids in milk fat and increased mono- and polyunsaturated fatty acids. The extruded soybean meal diets also increased urinary urea nitrogen excretion.

http://dx.doi.org/10.3168/jds.2015-9786.

Short communication: Grazing pattern of dairy cows that were selected for divergent residual feed intake as calves. By Gregorini et al., page 6486. The grazing pattern of dairy cows selected for divergent residual feed intake as calves was investigated when grazing pasture. The results support the concept that animals selected for divergent residual feed intake early in life may develop different strategies of herbage ingestion-energy acquisition as adults.

http://dx.doi.org/10.3168/jds.2015-9614.

Short communication: Artificial ultraviolet B light exposure increases vitamin $D$ levels in cow plasma and milk. By Jakobsen et al., page 6492. We tested the ability of a specially designed ultraviolet B (UVB) lamp to increase vitamin D levels in milk from dairy cows housed indoors. We found a significant increase in vitamin D levels in milk after cows were exposed daily to artificial UVB light for $24 \mathrm{~d}$. Extending the daily exposure to $73 \mathrm{~d}$ did not lead to an increase in vitamin $\mathrm{D}$ level in the milk. In conclusion, the decrease in vitamin $\mathrm{D}$ content in dairy products derived from cows with no access to pasture or sunlight may be elevated by UVB exposure in the stable.

http://dx.doi.org/10.3168/jds.2014-9277.

Evaluation of genomic selection for replacement strategies using selection index theory. By Calus et al., page 6499. Genomic selection can be used at the herd level to prioritize heifers for replacement. The potential benefit depends on the additional genotyping costs versus the additional revenues from using better heifers. The benefit of using genomic selection for replacement can be optimized by performing a preselection step based on parent average, which helps to reduce the overall genotyping cost. Our results indicate that the benefit of genomic selection to prioritize heifers for replacement appears to be higher than anticipated in previous studies.

http://dx.doi.org/10.3168/jds.2014-9192.

Overlap in genomic variation associated with milk fat composition in Holstein Friesian and Dutch native dual-purpose breeds. By MauriceVan Eijndhoven et al., page 6510. Similarities in genomic variation associated with milk fat composition 
in Holstein Friesian were investigated between Holstein Friesian and Dutch native dual-purpose breeds. In genomic regions associated with milk fat composition in Holstein Friesian, less variation was observed in the dual-purpose breeds. This indicates that Dutch native dual-purpose cattle breeds do not add to the genetic variability of the major fatty acids in milk observed in the mainstream breeds.

http://dx.doi.org/10.3168/jds.2014-9196.

Genomic prediction of dry matter intake in dairy cattle from an international data set consisting of research herds in Europe, North America, and Australasia. By de Haas et al., page 6522. In this study, we demonstrated that using dairy cattle dry matter intake (DMI) phenotypes and genotypes from multiple populations increases the accuracy of genomic breeding values (gEBV) for this important trait, provided a multi-trait approach is used. Data from research herds in Europe, North America, and Australasia were combined to estimate the accuracy of genomic prediction for DMI using multi-trait models. The mean accuracy of prediction was 0.44 , ranging from 0.37 (Denmark) to 0.54 (the Netherlands). http://dx.doi.org/10.3168/jds.2014-9257.

An alternative approach to modeling genetic merit of feed efficiency in dairy cattle. $B y L u$ et al., page 6535. Although improving feed efficiency (FE) is of increasing interest to dairy scientists, there has been considerable controversy on how to best characterize FE, particularly from the perspective of genetic evaluation. Two competing strategies are based on the analysis of residual feed intake (RFI) versus the analysis of dry matter intake (DMI). We demonstrate the equivalencies and differences between these two approaches provided that DMI is jointly analyzed with key energy-sink traits like milk energy and metabolic body weight in a multiple trait (MT) analysis. Our proposed measure of FE is based on Cholesky decompositions of the corresponding variance-covariance matrices from the MT analysis. This proposed measure further extends RFI by expressing the partial relationships between DMI and energy-sink traits separately at both genetic and nongenetic levels. By simulation, we demonstrate that our proposed approach does lead to higher accuracies in estimated breeding values (EBV) compared with RFI analyses when the discrepancies between these partial relationships at the genetic versus nongenetic levels are large; nevertheless, an application to dairy consortium data demonstrated no significant differences in cross validation prediction accuracy or appreciable differences in EBV.

http://dx.doi.org/10.3168/jds.2015-9414.

Characterization of microRNA in bovine in vitro culture media associated with embryo qual- ity and development. By Kropp and Khatib, page 6552. MicroRNAs are small RNA molecules that have recently demonstrated strong potential as biomarkers in the extracellular environment. Here, we identified differentially expressed microRNAs present in in vitro culture medium conditioned by embryos of differing developmental potential. The presence of microRNAs in the medium greatly affects the development of embryos by altering target mRNA expression within the embryo. These markers offer potential as a noninvasive method for better assessing embryos that will result in pregnancy, thereby improving reproductive efficiency in dairy cattle.

http://dx.doi.org/10.3168/jds.2015-9510.

Genetic relationships between claw health traits of dairy cows in different parities, lactation stages, and herds with different claw disorder frequencies. By van der Spek et al., page 6564. Limited knowledge is available on whether claw health traits are genetically similar in different parities, lactation stages, or herds with different claw disorder frequencies. Analyses revealed that sole hemorrhage and infectious lesions were genetically different across parities. White line separation and infectious lesions were not the same, genetically, in early and late lactation, and sole ulcer was genetically different in herds with different sole ulcer frequency. Convincing evidence for using a multi-trait model for claw health was not found.

http://dx.doi.org/10.3168/jds.2015-9561.

Short communication: Predictive ability of Fourier-transform mid-infrared spectroscopy to assess $C S N$ genotypes and detailed protein composition of buffalo milk. By Bonfatti et al., page 6583. Fourier-transform infrared spectra calibration equations were estimated to predict the detailed protein composition of individual milk samples of Italian Mediterranean buffalo (Bubalus bubalis). Infrared spectroscopy is not suitable for the prediction of detailed milk protein composition when a high accuracy is required, but calibration models might be used as a tool to provide breeding organizations with phenotypes on indicator traits for milk protein composition.

http://dx.doi.org/10.3168/jds.2015-9730.

Estimation of risk management effects on revenue and purchased feed costs on US dairy farms. By Hadrich and Johnson, page 6588. Variations in milk and feed prices directly affect dairy farm risk management decisions. This research used data from the 2010 USDA-ARMS Phase III dairy survey to determine how dairy farm decision-makers manage risk. Results of the study show that that dairy farms located in the Midwest and eastern United States benefit from selling milk to a cooperative and using commodity contracts to sell grain. Using a nutritionist was found to increase total 
feed costs across the United States, whereas feeding more than $65 \%$ of all forage from homegrown sources decreased total feed costs.

http://dx.doi.org/10.3168/jds.2014-8864.

Development and validation of a visual body condition scoring system for dairy goats with picture-based training. By Vieira et al., page 659\%. Body condition score has been widely used as a welfare indicator. However, its inclusion in on-farm welfare protocols presents some constraints. We addressed the difficulty of goat restraint by building a visual body condition scoring system that was developed by identifying representative images of 3 body condition categories: very thin, normal, and very fat goats. The scoring system, assessed for validity and reliability, is a practical tool for a quick first step assessment of fat reserve changes that affects an animal's welfare, health, and production.

http://dx.doi.org/10.3168/jds.2015-9428.

Concentration of mycotoxins and chemical composition of corn silage: A farm survey using infrared thermography. By Schmidt et al., page 6609.
Corn silage is a major supplemental forage for dairy cattle worldwide. This feed is susceptible to mycotoxin contamination during the pre- and postharvest production phases. Poor management of a silo face can lead to silage spoilage, heat, and mycotoxin production. In a farm survey, the temperature of a silo face was used to identify sampling sites at which to evaluate the chemical composition and concentration of mycotoxins of 327 samples from 109 Brazilian farms.

http://dx.doi.org/10.3168/jds.2014-8617.

Prediction of bovine milk technological traits from mid-infrared spectroscopy analysis in dairy cows. By Visentin et al., page 6620. The potential of mid-infrared spectroscopy in predicting milk coagulation properties, heat coagulation time, casein micelle size, and $\mathrm{pH}$ was evaluated using data from dairy cows fed a basal grazed-grass diet. Good predictive ability was obtained for all studied traits with the exception of casein micelle size and curd firmness $60 \mathrm{~min}$ from rennet addition. The developed prediction models may be useful to routinely and rapidly predict milk technological properties in milk from Irish cows at negligible cost. http://dx.doi.org/10.3168/jds.2015-9323. 